\title{
Neospora caninum Y OTROS AGENTES EN FETOS ABORTADOS DE BOVINOS LECHEROS DEL VALLE DE LIMA
}

\author{
Hermelinda Rivera G. ${ }^{1}$, Dennis Nelson ${ }^{2}$ y Luis Tabacchi N. ${ }^{3}$
}

\section{Whitrot}

The possible role of Neospora caninum and other abortogenic infectious agents in dairy cattle abortions was evaluated utilizing samples collected from 9 herds in the Lima Valley between January 1998 and December 1999. Heart, liver, lung, muscle, thymus, spleen, adrenal gland, brain and thoracic fluid samples were taken from 29 aborted 3-7 month gestation fetuses, and serum samples were collected from their mothers. The presence of antigens and antibodies against $N$. caninum, bovine diarrhea virus (BVDV), Brucella abortus and Leptospira was determined utilizing immunoperoxidase, immunofluorescence, virus neutralisation, indirect ELISA and microaglutination tests respectively. One half of the tissue samples were fixed for histopathological examination. Of the aborted fetuses, $55.2 \%(16 / 29)$ and $20.6 \%(6 / 29)$ were positive to $N$. caninum antigen and BVDV. $N$. caninum antibodies with titers between 1:20 and 1:40 were detected in three of the fetuses, but no antibodies against BVDV or Leptospira were found. Antibodies against $N$. caninum and BVDV were detected in 62\% (18/29) and $72.4 \%(21 /$ 29) of the aborted cows. No antibodies against either Brucella abortus or the Leptospira serovars canicola, pomona, icterohemorrhagiae, and hardjo were detected. Two of the fetuses had histopathological lesions (moderate inflammation with small areas of necrotic tissue in the brain, heart, muscle and thymus tissues) similar to those described in the literature. The high prevalence of $N$. caninum antigen in fetuses from positive cows and the moderate presence of BVDV contrasts with the absence of other abortogenic agents, strongly suggesting an association of $N$. caninum with the high incidence of abortion in dairy cows from the Lima Valley.

Key words: Bovine, fetus, abortion, BVDV, Neospora caninum, antibodies, antigen, immunohistochemistry.

El objetivo del presente estudio fue investigar la presencia de Neospora caninum, además de los principales agentes infecciosos abortogénicos como causantes de abortos en bovinos lecheros del Valle de Lima, de enero de 1998 a diciembre de 1999. Con este fin se trabajaron 29 fetos abortados entre 3 a 7 meses de edad y muestras de suero de sus respectivas madres procedentes de 9 hatos lecheros. Los fetos fueron necropsiados para la obtención de muestras de: corazón, hígado, pulmón, músculo, timo, bazo, glándula adrenal, cerebro y fluido toráxico. Las muestras fetales y suero de las vacas fueron procesadas para la detección de antígeno y anticuerpos contra $N$. caninum, el virus de la

1 Laboratorio de Microbiología IVITA - FMV - UNMSM. E.mail: d1700029@unmsm.edu.pe.

2 Veterinary Science Department, South Dakota State University, USA.

3 Laboratorio de Histopatología IVITA - FMV - UNMSM 
diarrea viral bovina (VDVB), Brucella abortus y Leptospira sp., mediante las pruebas de inmunoperoxidasa, inmunofluorescencia, virus neutralización, ELISA indirecta y microaglutinación, respectivamente. Parte de las muestras de tejidos fetales fueron fijados para estudios histopatológicos. El 55.2\% (16/29) de los fetos estudiados presentaron antígeno de $N$. caninum y el $20.6 \%$ (6/29) del VDVB. Anticuerpos contra $N$. caninum fue detectado en fluidos toráxicos de tres fetos de 5 y 6 meses con títulos entre 1:20 y $1: 40$ pero no se detectaron anticuerpos contra el VDVB ni Leptospira. El 62,1\% (18/29) de las vacas abortadas presentaron anticuerpos contra $N$. caninum y el $69,0 \%$ (20/29) contra el VDVB. No se detectaron anticuerpos contra cuatro serovares Leptospira tampoco contra Brucella abortus. Las lesiones histopatológicas en cerebro, corazón, músculo y timo de dos de los fetos consistieron en focos inflamatorios moderados con pequeñas áreas de necrosis. La alta prevalencia de antígeno de $N$. caninumen fetos de vacas seropositivas a $N$. caninum y la ausencia de anticuerpos contra los otros agentes abortogénicos sugieren la asociacion de $N$. caninum y en menor grado el VDVB en la presentacion de la alta incidencia de abortos en los bovinos de los hatos estudiados.

Palabras clave: Bovino, fetos, abortos, diarrea viral bovina, Neospora caninum, anticuerpos, antígeno, inmunohistoquímica.

\section{Introitcetin}

La ocurrencia de abortos en estadíos tempranos o tardíos de la gestación en bovinos lecheros del valle de Lima se han incrementado durante estos últimos años. La identificación de las causas de este problema, necesaria para un rápido control y evitar pérdidas económicas, es un desafio permanente para el veterinario y el ganadero y no siempre se tienen resultados exitosos. La dificultad en la identificación de las causas es debido a su múltiple etiología, dentro de las cuales, los agentes infecciosos pueden causar directa o indirectamente la pérdida del producto de la concepción en cualquier etapa de su desarrollo (Kirkbride, 1992; Thurmond y Picanso, 1990).

En el Perú, entre los agentes infecciosos abortogénicos de mayor importancia en ganado lechero de crianza intensiva o semi-intensiva figuran, el virus de la diarrea viral bovina (VDVB), Brucella abortus, Leptospira y en menor grado el herpes bovino tipo 1 (IBR). La responsabilidad de la Brucella abortus en la presentación de abortos en las principales cuencas lecheras, es cada vez menor debido a su baja prevalencia (< a 1\%), así mismo, preliminares estudios de seroprevalencia de la leptospirosis y el IBR en bovinos del valle de Lima, sugieren su escaso compromiso en la actual presentación de los abortos (Rivera $\mathrm{H}$, datos no publicados); mientras que, la DVB y la recientemente descrita Neospora caninum, son al parecer, los principales causantes de los problemas reproductivos en el ganado lechero (Rivera et al., 1993; Contreras, 2000; Andresen, 1999).

La $N$. caninum pertenece a un nuevo género de la familia Sarcocystidae con distribución mundial, habiéndo emergido en esta última década como una de las enfermedades reproductivas de mayor significancia económica para la industria bovina del mundo (Thurmondy et al., 1997; McAllister, 1999; Dubey, 1999). El aborto producido por $N$. caninum puede ocurrir a partir del tercer mes, hasta el término de la gestación, pero mayormente sucede entre el cuarto y sexto mes de gestación (Dubey y Lindsay, 1996). La vaca puede infectarse con el parásito por vía digestiva y permanecer infectada sin 
manifestar ningún signo clínico de enfermedad, pero, durante la preñez el parásito puede ser transmitido verticalmente al feto. $\mathrm{Al}$ parecer, el parásito ocasiona una placentitis primaria, de donde se distribuye en el tejido fetal vía sanguínea; como consecuencia, el feto puede morir y ser reabsorbido, momificado o eliminado (aborto). Por otro lado, el feto puede llegar a término, pero nacer muerto o débil y enfermo o clínicamente normal pero infectado (Dubey y Lindsay, 1996; Helman, et al., 1998; Hemphill, 1999).

La detección de bovinos reactores a $N$. caninum procedentes de Arequipa, donde la incidencia de abortos supera al $20 \%$ y posteriormente de bovinos lecheros del valle de Lima, permitieron considerar a este parásito como una de las posibles causas de aborto (datos no publicados) por lo que se llevó a cabo el presente trabajo.

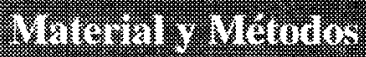

\section{Colección de Muestras}

Se estudiaron 29 fetos abortados entre tres a siete meses de edad y sueros de sus respectivas madres procedentes de nueve hatos lecheros. Los fetos fueron necropsiados en busca de posibles lesiones y colección de tejidos de: corazón, pulmón, hígado, timo, músculo esquelético, glándula adrenal, cerebro y fluido toráxico para la detección de antígenos y anticuerpos de $N$. caninum, VDVB y Leptospira; parte de los tejidos fueron fijados para estudios histopatológicos. Al momento del aborto se colectaron muestras de sangre de las vacas $(\mathrm{n}=29)$ para la detección de anticuerpos contra la $N$. caninum, VDVB, Brucella abortus y Leptospira.

\section{Detección de antígenos de $\boldsymbol{N}$. caninum y VDVB.}

La detección de antígeno de $N$. caninum en los tejidos fetales fue mediante la prueba de inmunoperoxidasa, empleando suero hiperinmune contra $N$. caninum como anticuerpo primario de procedencia comercial (VMRD) y el kit ABC (Vector Laboratories) de acuerdo al protocolo descrito por las respectivas compañías comerciales, y el antígeno de VDVB mediante la prueba de inmunoflurescencia directa empleando como conjugado un suero antiVDVB policlonal de procedencia comercial (NVS Ames, IOWA, USA).

\section{Detección de anticuerpos contra $N$. caninum y VDVB}

Los anticuerpos contra $N$. caninum en las muestras de suero diluido1:200 de las vacas que abortaron y fluidos fetales en diluciones dobles a partir de 1:20 fueron detectados mediante la prueba de inmunofluorescencia indirecta, utilizando el conjugado de procedencia comercial y el protocolo descrito por la misma compañía (VMRD) y los anticuerpos contra el VDVB mediante la prueba estándar de virus neutralización. Los anticuerpos contra Brucella abortus y los serovares: canicola, pomona, icterohemorrhagiae y hardjo de Leptospira en los sueros de las vacas abortadas fueron detectados mediante las pruebas de ELISA indirecta y microaglutinación respectivamente.

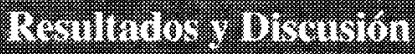

El 55.2\% (16/29) de los fetos estudiados presentaron antígeno (quistes) de $N$. caninum y el $20.7 \%(6 / 29)$ del VDVB (Cuadro 1). En la Figura 1, se presenta el antígeno (quistes) de $N$. caninum en cortes 
Cuadro 1. Distribución de fetos abortados según edad y presencia de antígenos de $N$. caninum y VDVB, mediante las pruebas de inmunoperoxidasa $\mathrm{e}$ inmunofluorescencia, respectivamente.

\begin{tabular}{cccccc}
\hline \multirow{2}{*}{$\begin{array}{c}\text { Edad fetos } \\
\text { (meses) }\end{array}$} & \multirow{2}{*}{\begin{tabular}{c} 
Fetos, \\
\cline { 3 - 6 }
\end{tabular}} & $\mathrm{n}$ & \multicolumn{4}{c}{ P. caninum } & Presencia de antígenos de \\
\cline { 3 - 6 } & 14 & 8 & 57.1 & 4 & \multicolumn{3}{c}{ VDVB } \\
\hline $3-4$ & 15 & 8 & 53.3 & 2 & 13.3 \\
577 & 29 & 16 & 55.2 & 6 & 20.7 \\
Total & 29 & & & & \\
\hline
\end{tabular}

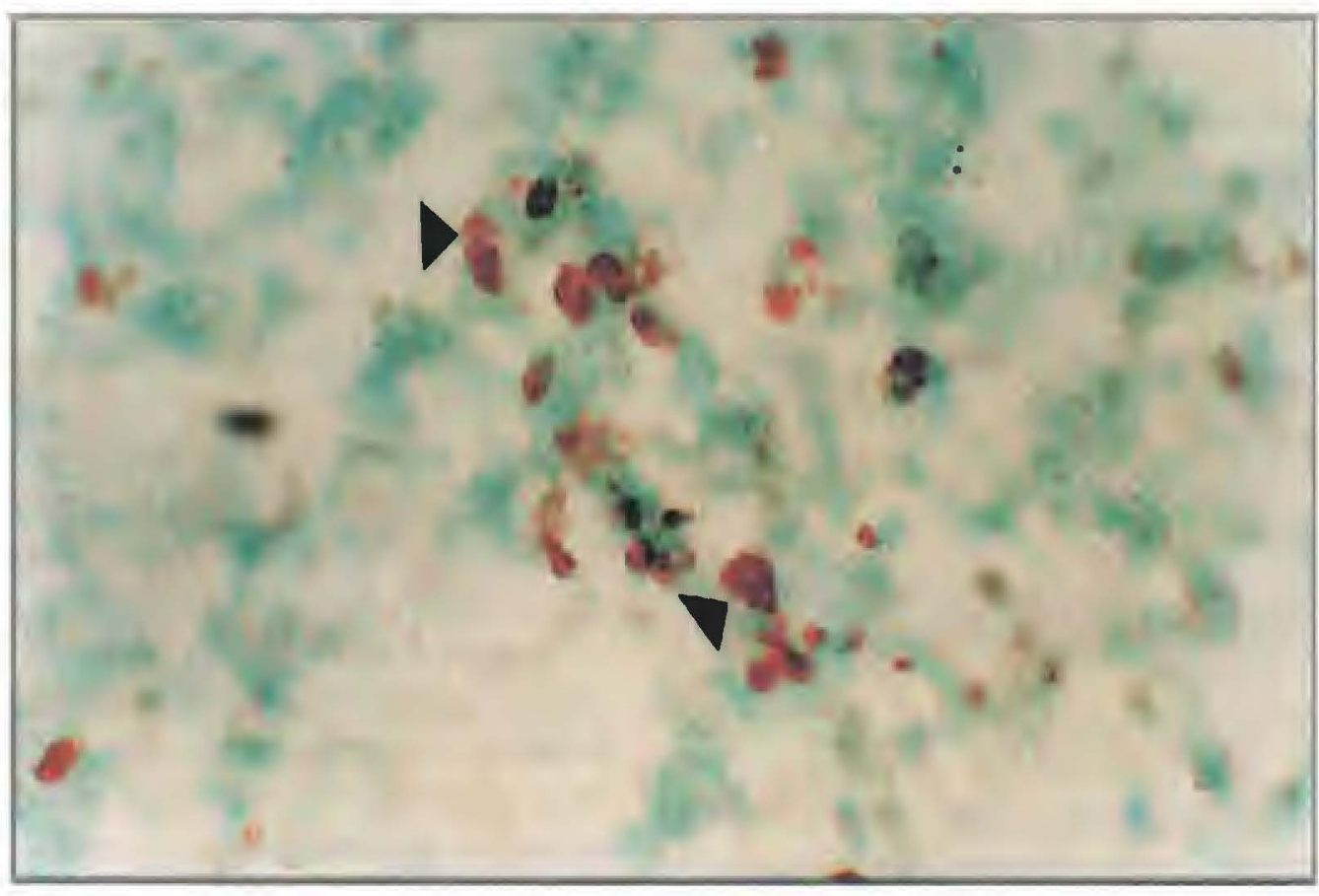

Figura 1. Corte en congelación del músculo cardiaco de un feto de cuatro meses. Nótese la presencia de quistes de $N$. caninum mediante la prueba de inmunoperoxidasa. 40X.

en congelación del músculo cardiaco. Por otro lado, se detectaron anticuerpos contra N. caninum en tres de los fetos de cinco y seis meses con títulos entre 1:20 y 1:40.

La lesión histopatológica en tejidos de dos fetos de 4 y 4.5 meses de edad, fue caracterizada por presencia de focos inflamatorios moderados con infiltración de células mononucleares y pequeñas áreas de necrosis, no observándose quistes. Estas lesiones fueron más evidentes en el corazón, cerebro y músculo esquelético (Fig. 2).

En el suero de las vacas que abortaron se detectaron anticuerpos contra $N$. caninum en el $62.1 \%(18 / 29)$ y contra el VDVB en el 69.0\% (20/29) (Cuadro 2), no detectándose anticuerpos contra $B$. abortus ni Leptospira. 
Cuadro 2. Detección de anticuerpos contra el VDVB y $N$. caninum en vacas que abortaron.

\begin{tabular}{cccc}
\hline Hatos No. & Vacas que abortaron, & \multicolumn{2}{c}{ Anticuerpos contra: } \\
\cline { 3 - 4 } & $\mathrm{n}$ & 1 & $\mathrm{~N}$. caninum \\
\hline 1 & 1 & 5 & 0 \\
2 & 8 & 7 & 8 \\
3 & 8 & 0 & 1 \\
4 & 1 & 5 & 1 \\
5 & 5 & 0 & 5 \\
6 & 1 & 1 & 1 \\
7 & 1 & 1 & 0 \\
8 & 2 & NR & 1 \\
9 & 2 & $20(69.0 \%)$ & 1 \\
\hline Total & 29 & & $18(62.1 \%)$ \\
\hline
\end{tabular}

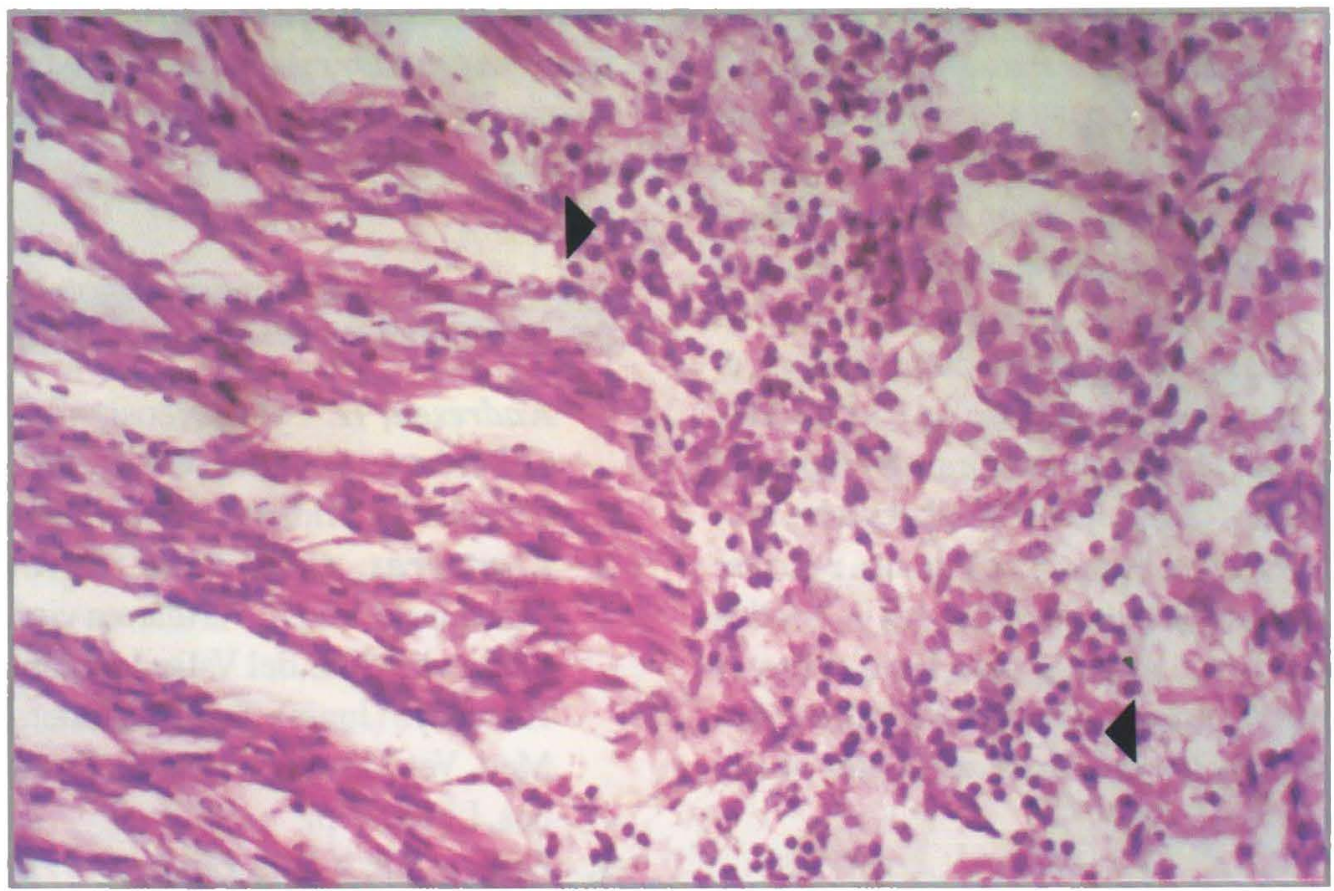

Figura 2. Corte histopatológico de músculo esquelético. Nótese la presencia de lesión focal con infiltración moderada a base de células inflamatorias mononucleares. Coloración H-E.

La presencia de quistes de $N$. caninum en el 55.2\% (16/29) de los fetos estudiados, procedentes de vacas seropositivas al momento del aborto, confirman los previos estudios serológicos de la neosporosis en el Perú (Cuadros 1 y 2).
La detección de anticuerpos contra $N$. caninum en fluidos toráxicos en tres de los fetos con títulos de 1:20 y 1:40 indican sin duda una infección prenatal. No se detectaron anticuerpos en el resto de los fetos positivos a $N$. caninum, a diferencia 
de lo manifestado por Wouda et al. (1997) que detectaron anticuerpos contra $N$. caninum en fluidos toráxicos en $65 \%$ (48/ 90) de los fetos con títulos entre 1:25 a 1:800. El fluido fetal es una buena muestra para detectar infecciones congénitas, pero la deteccion de anticuerpos en sólo tres de los fetos podría deberse a factores como: inmadurez inmunológica de algunos fetos, predominancia de IgM en lugar de IgG o degradación de las inmunoglobulinas por la severa autolisis o probablemente debido a un reducido número de fetos estudiados. No se detectaron anticuerpos aglutinantes contra los cuatro serovores de la Leptospira en los fluidos fetales.

En el presente estudio sólo se realizó el examen histopatológico de dos de los fetos de 4 y 4.5 meses de edad y en ambos casos se observaron discretas lesiones focales caracterizadas por infiltraciones de células gliales y pequeñas áreas de necrosis, pero ausencia de quistes en el cerebro, observándose infiltraciones mononucleares en las fibras del músculo cardiaco y otros tejidos, similares a los descritos en la literatura. Las lesiones poco severas podrían deberse a la edad de los dos fetos ( 4 y 4.5 meses), pues fetos mayores de cinco meses desarrollan respuestas inflamatorias más severas (Otter et al., 1995).

La ausencia de B. abortus y Leptospira y la presencia de anticuerpos contra $N$. caninum en $62.1 \%$ de vacas al momento del aborto (Cuadro 2) y la detección de quistes de $N$. caninum en el $55.2 \%$ de los fetos abortados (Cuadro 1), es una evidencia de que la neosporosis es una importante causa de abortos en bovinos lecheros de los hatos estudiados. El $78.0 \%$ (7/9) de los hatos de donde procedieron las vacas, estuvieron infectados con $N$. caninum (Cuadro 2), confirmándose el concepto de que vacas seropositivas a $N$. caninum tiene un riesgo de dos a tres veces mayor de abortar que las vacas negativas (Quintanilla-Gozalo et al., 1999).

La detección de antígeno del VDVB en el $20.7 \%$ (6/29) de los fetos significa una infección prenatal con virus de campo, a pesar de ser difícil su asociación con los abortos, debido a la alta prevalencia de la infección subclínica (69.0\%) en vacas que abortaron, sin embargo, no se descarta su rol en la presentación de los abortos, sobre todo en las pérdidas embrionarias. La presencia simultánea de antígeno del VDVB y $N$. caninum en dos de los fetos significa la ocurrencia de infecciones concomitantes en las vacas y talvez este sinergismo podría incrementar el riesgo del aborto.

\section{Titeritura Cimb:}

1. Andresen, H. 1999. Neosporosis en el Perú y el mundo. MV Revista de Ciencias Veterinarias. 15(4):11-16.

2. Contreras, G.H. 2000. Seroprevalencia del virus de la diarrea viral bovina en bovinos del Valle del Mantaro, Huancayo (Junín). Tesis Bachiller. Fac. Med. Vet. Univ. Nac. Mayor San Marcos, Lima. 43p.

3. Dubey, J.P. y D.S. Lindsay. 1996. A review of Neospora caninum and neosporosis. Vet Parasitol. 67:1-59.

4. Dubey, J.P. 1999. Neosporosis in cattle: biology and economic impact. JAVMA. 214 (8):1160-1163.

5. Helman, R.G.; E.L. Stair; T.W. Lehenbauer; S. Rodgers y J.T. Saliki. 1998. Neosporal abortion in Oklahoma cattle with emphasis on the distribution of brain lesions in aborted fetuses. J Vet Diagn Invest. 10:292295. 
6. Hemphill, A. 1999. The host-parasite relationship in neosporosis. Adv in Parasitol. 43: 47-104.

7. Kirkbride, C. 1992. Etiologic agents detected in a 10 year study of bovine abortions and stillbirths. J Vet Diagn Invest. 4:175-180.

8. McAllister, M.M. 1999. Uncovering the biology and epidemiology of Neospora caninum. Pararitology Today. $15(6): 216-217$.

9. Otter, A.; M. Jeffrey; I.B. Griffiths y J.P. Dubey. 1995. A survey of the incidence of Neospora caninum infection in aborted and stillborn bovine fetuses in England and Wales. Vet Rec. 136: 602-606.

10. Quintanilla-Gozalo, A.; J. Pereirabueno.; E.Tabarés.; E.A. Innes, $R$. Gonzáles-Paniello y L.M. OrtegaMora. 1999. Seroprevalence of Neospora caninum infection in dairy and beef cattle in Spain. Int $\mathbf{J}$ for Parasitol. 29: 1201-1208.

11. Rivera, H.; A. Manchego.; N. Sandoval; A. Vargas; A. Araujo; $A$. Gonzalez y R. Rosadio. 1993. Aborto infeccioso en bovinos de leche del valle de Lima. Rev Inves Pec (Perú). 6 (1): 31-37. 